Ensino, Saúde e Ambiente - V5 (2), pp. 186-197, ago. 2012

\title{
CONSUMO CONSCIENTE: ELABORAÇÃO DE UM JOGO VIRTUAL COMO CONTRIBUIÇÃO À EDUCAÇC̃̃̃ AMBIENTAL
}

\section{SUSTAINABLE DEVELOPMENT: VIRTUAL GAME CONTRIBUTION TO ENVIRONMENTAL EDUCATION}

\author{
Débora Cristina Lopes Martins ${ }^{1}$, Valéria da Silva Vieira ${ }^{2}$, Rosana Aparecida Ravaglia \\ Soares $^{3}$, Denise Celeste Godoy de Andrade Rodrigues ${ }^{4}$
}

${ }^{1}$ Centro Universitário de Volta Redonda UniFOA/PROMES/ Mestrado em Ensino em Ciências da Saúde e do Meio Ambiente, debora.martins@foa.org.br

${ }^{2}$ Centro Universitário de Volta Redonda UniFOA/PROMES/ Mestrado em Ensino em Ciências da Saúde e do Meio Ambiente, valeria.vieira@foa.org.br

${ }^{3}$ Centro Universitário de Volta Redonda UniFOA/PROMES/ Mestrado em Ensino em Ciências da Saúde e do Meio Ambiente, rosana.ravaglia@foa.org.br; Associação Educacional Dom Bosco AEDB, rravaglia@gmail.com

${ }^{4}$ Centro Universitário de Volta Redonda UniFOA/PROMES/ Mestrado em Ensino em Ciências da Saúde e do Meio Ambiente, denise.rodrigues@ foa.org.br; Universidade do Estado do Rio de Janeiro UERJ/

DEQA/ FAT, denisegodoy@uerj.br

\section{RESUMO}

A educação ambiental no Brasil tem se fortalecido nos últimos anos, sendo considerada indispensável para despertar a consciência das pessoas. O consumo consciente dos recursos está inserido na temática ambiental, constituindo-se em tema longamente debatido e disseminado entre educadores ambientais. Diante disso, propõe-se neste trabalho um jogo virtual sobre consumo consciente que servirá de apoio para disseminação desta temática na sociedade como um todo. Apresentamos uma pesquisa exploratória que foi utilizada para verificar o conhecimento prévio e a disposição para participar do jogo, de funcionários de uma instituição de ensino superior, localizada no interior do Estado do Rio de Janeiro, na cidade de Volta Redonda. A pesquisa apontou um bom conhecimento dos participantes acerca da temática, disposição para participar do jogo no site institucional e o jogo de trilha como o preferido da maioria. Neste trabalho são mostrados o jogo e um site relacionado ao mesmo.

Palavras-chave: Educação ambiental, desenvolvimento sustentável, jogo virtual

\begin{abstract}
Environmental education in Brazil has been strengthened in recent years and is considered essential to awaken people's consciousness. The conscious consumption of resources is inserted into the environmental theme, which makes it an issue long debated and disseminated among environmental educators. Therefore, this paper proposes a virtual game on conscious consumption that will support for the dissemination of this issue in society as a whole. We present an exploratory research that was used to determine prior knowledge and willingness to participate in the game, in an institution of higher education located at Volta Redonda city in the State of Rio de Janeiro. The results showed a good knowledge of participants about the subject, willingness to play the game in the institutional site and play the track as the most preferred. In this study, we describe the game and a website related to it.
\end{abstract}

Key words: Environmental Education, sustainable development, virtual game 


\section{INTRODUÇÃO}

A Educação Ambiental é um tema que tem despertado na sociedade uma reflexão sobre a nossa responsabilidade em contribuir para que as gerações futuras possam ter acesso aos recursos naturais, tal como temos hoje, garantindo a continuidade da vida na Terra.

De uma forma geral, a sociedade pode contribuir adotando práticas de consumo consciente garantindo que o mau uso e o desperdício de recursos deixem de fazer parte da rotina diária do ser humano.

Para iniciar a abordagem sobre consumo consciente, necessário se faz entender, antes, o conceito de educação ambiental, uma vez que somente a educação é capaz de promover mudanças de comportamento significativas. A mudança de comportamento é base necessária para adoção da prática do consumo consciente, tema do presente estudo.

Segundo Junior e Pelicioni (2002), a educação ambiental é um processo de educação política que possibilita a aquisição de conhecimentos e habilidades, bem como a formação de atitudes que se transformam necessariamente em práticas de cidadania que garantem uma sociedade sustentável.

No cenário mundial, a educação ambiental passou a ser tema de relevância na década de 70. No entanto, nessa época, o enfoque naturalista esteve presente na maior parte das discussões, motivado, principalmente, pelas inúmeras manifestações ambientalistas que denunciavam a destruição da natureza causada pelo homem. Portanto, os debates concentravam-se na relação entre desenvolvimento social e econômico e seu impacto na questão ambiental. Dias (2004), relata uma experiência com um grupo de alunos, onde a proposta era que os mesmos fizessem uma lista dos animais encontrados na fauna urbana, ou seja, na cidade. "Curiosamente, na maioria das vezes, os alunos demoraram muito para incluir o ser humano nas suas listas, quando não o omitiram completamente. Esse pode ser o reflexo de uma educação que enfatiza a soberania humana sobre a natureza" (DIAS, 2004, p. 258).

No ensino de Ciências e em eventos científicos, como nos Encontros Nacionais de Pesquisa em Educação em Ciências (ENPEC - criado em 1997), a Educação Ambiental (EA) também passou a ser um dos temas discutidos, culminando na criação de uma área temática específica denominada "Educação Ambiental e Ensino de Ciências" (KAWASAKI e CARVALHO, 2009). Neste evento, observou-se o 
crescimento no número de trabalhos nesta área do primeiro ao quinto evento, posteriormente, pesquisadores ressaltaram, também, um aumento considerável, no cenário acadêmico de eventos científicos específicos em EA (KAWASAKI et al, 2009).

Embora historicamente a concepção de meio ambiente esteja associada à ecologia e o homem utilize seus recursos finitos num modelo de gestão capitalista que visa lucro a todo custo, sem se preocupar com os impactos ambientais e sociais de tais práticas, é importante percebermos que essa concepção vem mudando.

Rodrigues e Colesanti (2008) abordam o fato de que nas últimas décadas, os esforços de vários países e movimentos organizados em prol da preservação do meio ambiente, vêm buscando diminuir os impactos causados pela ação humana, os quais são geradores de degradação ambiental.

Nesse contexto, as práticas de Educação Ambiental se intensificaram com objetivo de informar e sensibilizar as pessoas e a sociedade em geral sobre a necessidade da adoção de práticas que contribuam para a preservação ambiental. Dentre as ações implementadas, Rodrigues e Colesanti (2008), citam a inclusão de temas ambientais no sistema educacional básico, a formação de pessoal necessário ao desenvolvimento da Educação Ambiental, criação de cursos de pós-graduação lato sensu e scricto sensu para professores e outros profissionais, além da elaboração de materiais didáticos, audiovisual ou impresso.

Além das ações citadas anteriormente, observa-se também a inserção de temas relacionados à Educação Ambiental em congressos e fóruns. No meio digital, podemos acompanhar a utilização de redes sociais e a criação de sites relativos a este tema, o que favorece conceitos, antes restritos ao meio acadêmico, sejam veiculados também em mídias de massa, democratizando o acesso à informação, favorecendo que temas relacionados à Educação Ambiental possam ser compartilhados fora do ambiente da educação formal.

Nesse sentido, é interessante mencionar Jacobi (2003, p.192) que afirma:

Nestes tempos em que a informação assume um papel cada vez mais relevante, ciberespaço, multimídia, internet e a educação para a cidadania representam a possibilidade de motivar e sensibilizar as pessoas para transformar as diversas formas de participação na defesa da qualidade de vida.

Refletindo sobre cidadania, podemos destacar o impacto do movimento CSTA (Ciência-Tecnologia-Sociedade-Ambiente) no ensino de ciências (CACHAPUZ et. al, 2005). Este movimento, que teve como último complemento a inserção de EA no 
tripé ciência-tecnologia-sociedade, objetiva o alcance da alfabetização científica para os estudantes, enfatizando o papel da cidadania na tomada de decisões.

Diante do exposto, o presente trabalho propõe a criação e implantação de um jogo virtual sobre o tema consumo consciente na área restrita do site institucional de um Centro Universitário da cidade de Volta Redonda.

Pretende-se com este jogo levar ao conhecimento do público alvo do presente estudo, informações educativas sobre consumo consciente de forma lúdica e atraente em um ambiente de educação não-formal. Através da interação possibilitada pelo jogo virtual pretendemos despertar nos usuários do site o interesse pela prática de consumo consciente, transformando essa prática em hábito permanente, uma verdadeira mudança de atitude em benefício da sociedade e, numa visão mais ampla, na preservação do meio ambiente para garantia de qualidade de vida das gerações futuras. Após implementação e teste na área restrita, pretende-se disponibilizar o jogo no site institucional, fora da área restrita, com acesso público, a fim de torná-lo um produto disseminável.

\section{JOGO VIRTUAL COMO ESTRATÉGIA PARA DESPERTAR O CONSUMO CONSCIENTE}

O jogo faz parte da vida do homem desde os primórdios da civilização. Quando ainda não existia a escrita, o homem utilizava gestos e sons para expressar-se e fazer-se entender pelo grupo. De acordo com Kishmoto (2001), o jogo possui duas funções gerais essenciais, uma lúdica, enquanto propicia diversão, prazer e até o desprazer; outra educativa, por ensinar qualquer coisa que complete o indivíduo em seu saber, seus conhecimentos e seu posicionamento com o mundo.

Além do aspecto social a que remete, o jogo tem papel fundamental na educação, uma vez que, antes de ser apenas uma atividade lúdica, o jogo é um instrumento através do qual as pessoas exercitam habilidades necessárias ao seu desenvolvimento integral, dentre elas, autodisciplina, sociabilidade, afetividade, valores morais, espírito de equipe e bom senso (GRAMIGNA, 2007).

Segundo Kanaaene e Abussandra (2008, p.84),

Antes de constituir-se em atividade lúdica, o jogo é um instrumento muito importante nos processos de educação em geral. Por meio dele, as pessoas exercitam habilidades necessárias para seu desenvolvimento integral, assim como a autodisciplina, sociabilidade, afetividade, valores morais, espírito de equipe, bom senso, criatividade, espontaneidade e iniciativa. 
Huizinga (apud Kishimoto, 2003), aponta características para os jogos que, segundo o autor, são produzidas pelo meio social. Entre essas características, ele destaca o prazer, o caráter "não-sério", a liberdade, a separação dos fenômenos do cotidiano, as regras, o caráter fictício ou representativo e sua limitação no tempo e no espaço.

Para Gramigna (2003), “o jogo é uma atividade espontânea, realizada por mais de uma pessoa, regida por regras que determinam quem vencerá. Essas regras incluem o tempo de duração, o que é permitido e proibido, valores das jogadas e indicadores sobre como terminar a partida."

Quando a autora, em sua definição, afirma que o jogo é uma atividade realizada por mais de uma pessoa, ela não exclui os jogos de computadores e considera que o xadrez jogado no computador, por exemplo, pressupõe a existência de dois personagens: o que está diante do monitor e o idealizador do jogo, presente em sua capacidade inventiva. Para Fernandes et al, os jogos no computador representam um universo de interação usuário-interface muito mais exigente. Segundo o autor, o usuário de software, em geral, dá ênfase à qualidade da interface do mesmo em termos relativos, considerando sua praticidade em comparação ao ato de realizar a mesma tarefa sem o computador. No caso do jogo, esse deve passar por um teste "absoluto" devendo ser funcional, fácil de usar e divertido.

Para Silveira e Barone (2011), a utilização de jogos educativos computadorizados traz inúmeras vantagens à aprendizagem, principalmente porque se "aprende brincando".

O jogo, no entanto, está associado à recreação, divertimento, dentro de um espaço de tempo delimitado, sujeito a regras e avaliação, as quais devem estar bem definidas para que uma de suas principais características, o prazer, seja preservado.

O jogo virtual do consumo consciente, idealizado neste trabalho, é um jogo com interface lúdica, cujo objetivo é proporcionar a possibilidade de testar conhecimentos do cotidiano. O aprendizado será obtido através de um reforço de conceitos relativos ao consumo consciente de recursos naturais, proporcionado por meio de um jogo de trilha.

\section{METODOLOGIA}

Para realização do presente estudo e desenvolvimento do jogo e de um site educativo relacionado ao jogo, foi realizada pesquisa através de questionário semiestruturado, aprovada pelo Comitê de Ética (registro SIPAR 25.000.158.694/2007-89) 
processo 219/09. A pesquisa foi aplicada a funcionários técnico-administrativos do Centro Universitário de Volta Redonda - UniFOA e teve como objetivo identificar os conhecimentos prévios destes funcionários em relação a consumo consciente, bem como identificar a predisposição dos mesmos para participação em jogos. A instituição foi escolhida por haver um histórico de interesse da direção em dar continuidade à campanha educativa sobre consumo consciente realizada em 2009.

Após aprovação do Comitê de Ética sob protocolo 069925 de 14/12/2009, aplicou-se a o questionário, cuja amostra de 101 entrevistados foi definida considerando-se um nível de confiança de $95 \%$ e erro amostral de mais ou menos $5 \%$ e foi realizada durante em 2010.

Todos os entrevistados assinaram um termo de consentimento livre e esclarecido, tornando-se cientes do objetivo de pesquisa, bem como da possibilidade de desistência de preenchimento do questionário, sem ônus para o respondente.

Essa pesquisa apresentou perguntas relacionadas a conhecimentos prévios dos entrevistados acerca de consumo consciente e, principalmente, respaldou a decisão sobre a criação de um jogo virtual, uma vez que apontou o percentual de entrevistados que acessam a internet, a frequencia de uso e a pré-disposição dos mesmos para jogar, além de apontar o tipo de jogo mais desejado.

\section{ELABORAÇÃO DO JOGO CONSUMO CONSCIENTE}

O Software utilizado para o desenvolvimento do jogo virtual foi Adobe Flash CS4. O programa fornece ferramentas de animações com suporte à programação Action Script, onde é possível controlar o vídeo por códigos, a fim de gerar o resultado desejado.

O tempo de duração de criação do jogo foi de 52h30min, com uma média de 3h30min por dia.

As imagens do jogo virtual foram desenhadas à mão livre por um ilustrador e digitalizadas através do software Photoshop CS.

\section{DESENVOLVIMENTO DO SITE}

$\mathrm{O}$ site foi desenvolvido por um WebDesigner utilizando-se o programa Dreanweaver CS4, Adobe Flash CS4 e Photoshop CS. O site encontra-se hospedado na página do UniFOA sob o endereço: http://www.unifoa.edu.br/consumoconsciente. O tempo de duração de criação do site foi de $21 \mathrm{~h}$. O site encontra-se em fase de testes e de inserção de conteúdo. 
O site foi concebido com a mesma identidade visual do jogo virtual, possuindo as mesmas ilustrações. $\mathrm{O}$ acesso ao site pode ser feito diretamente pelo website do UniFOA ou através do jogo virtual, quando, ao final do jogo, abrirá uma opção com link para o site.

\section{RESULTADOS E DISCUSSÃO}

Os funcionários participantes da pesquisa encontram-se nas seguintes faixas etárias: a maioria, de 26 a 35 anos (35\%), 21\% entre 17 e 25 anos, 24\% entre 36 e 45 anos e $21 \%$ acima de 45 anos. Demonstrando que, pelo fato da maioria dos entrevistados se encontrarem abaixo de 45 anos (quase 80 respondentes) os mesmos situam-se numa faixa etária acostumada a utilizar o computador. Quanto à escolaridade dos respondentes, $53 \%$ possuem curso superior, $29 \%$ superior incompleto, $10 \%$ ensino médio, $2 \%$ ensino médio incompleto e $6 \%$ mestrado.

Com objetivo de identificar os conhecimentos prévios dos entrevistados (MORTIMER, 1994), foi feita uma pergunta relativa ao significado de consumo consciente: $82 \%$ dos entrevistados responderam que consumir conscientemente significa utilizar de forma responsável os recursos naturais; $16 \%$ respondeu que significa participar de campanhas educativas fornecendo ideias sobre redução de consumo aos colegas de trabalho; $2 \%$ afirmou que consumo consciente é a redução radical da utilização de recursos naturais. No entanto, $98 \%$ dos entrevistados disseram concordar que consumir conscientemente recursos como água e energia elétrica é uma forma de contribuir para a saúde financeira da empresa, bem como para a preservação do meio ambiente.

Os resultados relativos à associação que os entrevistados fazem da adoção do consumo consciente em relação à empresa são mostrados na Figura 1. Ao se observar a Figura 1 pode-se estabelecer três categorias de respostas. Na primeira categoria estão as respostas que relacionam a adoção de consumo consciente com questões ambientais, totalizando $49 \%$. A segunda categoria relaciona o consumo consciente com benefícios para a empresa e o ambiente (36\%). Já a terceira categoria, afirma que o consumo consciente está relacionado apenas com a questão financeira da instituição, sendo esta a resposta dada pela minoria dos respondentes (7\%). Isto mostra que a maioria dos entrevistados consegue associar corretamente as questões de consumo com o ambiente.

Para estudar a viabilidade da implantação de um jogo virtual sobre consumo consciente, os entrevistados foram questionados em relação ao acesso à área restrita do 
site do UniFOA, local onde pretendemos disponibilizar o jogo inicialmente. Dentre os entrevistados, 98\% afirmaram acessar a área restrita do site. Os resultados relativos a esta parte da pesquisa são mostrados na Tabela 1.

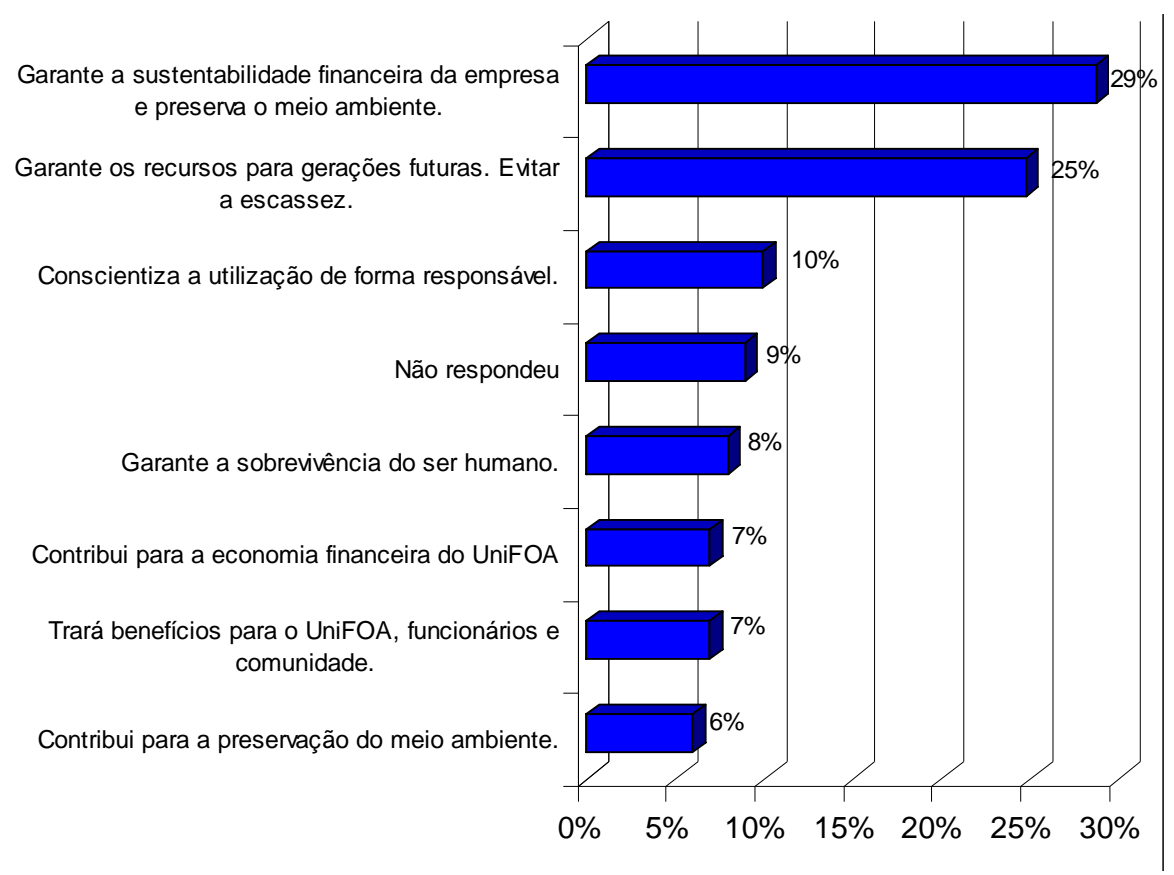

Figura 1: Relação entre a adoção do consumo consciente e a instituição de ensino.

Tabela 1: Resultados relativos à viabilidade de uso da área restrita do site do UniFOA para disponibilização do jogo virtual.

\begin{tabular}{l|l}
\hline Parâmetro & Resultado \\
\hline Frequência de acesso à área restrita do site & Diariamente: $78 \%$ \\
do UniFOA. & Três vezes por semana: 11\% \\
& Uma vez por semana: $8 \%$ \\
\hline $\begin{array}{l}\text { Predisposição para participar de um jogo } \\
\text { sobre o tema na área restrita. }\end{array}$ & Participaria: $64 \%$ \\
& Não sabe: $23 \%$ \\
& Não participaria: $10 \%$ \\
& Participaria com incentivo (brinde): $3 \%$ \\
\hline Frequencia de participação no jogo. & Semanalmente: $47 \%$ \\
& Mensalmente: $23 \%$ \\
& Quinzenalmente: $12 \%$ \\
\hline
\end{tabular}

Os resultados mostrados na Tabela 1 apontam que a maioria dos entrevistados acessa a área restrita, aceitaria participar do jogo sobre o tema, com frequiências diferenciadas. Isto demonstra que a estratégia do jogo é bem aceita pelos 
respondentes, sendo esta uma boa estratégia para a implantação e testagem inicial do produto deste trabalho.

Em relação às modalidades, os jogos mais citados foram trilha (31\%), jogo da memória (29\%), quebra-cabeças (21\%) e palavra cruzada $(16 \%)$.

Para o presente estudo, optou-se pelo jogo de trilha, modalidade mais representativa na pesquisa exploratória.

\section{O JOGO VIRTUAL CONSUMO CONSCIENTE}

O jogo virtual possui um ponto de partida onde o jogador deverá clicar sobre um dado que aleatoriamente e de forma automática, percorrerá o caminho do jogo parando na casa correspondente ao número indicado no dado (Figura 2). Nessa casa, o jogador poderá visualizar dicas sobre consumo consciente e meio ambiente ou então pergunta em formato de quiz (Figura 3) onde, acertando a resposta, o jogador acumula 100 pontos e errando não pontua. Para dar continuidade ao jogo, o jogador deverá clicar no dado na parte superior direita da pergunta ou curiosidade.

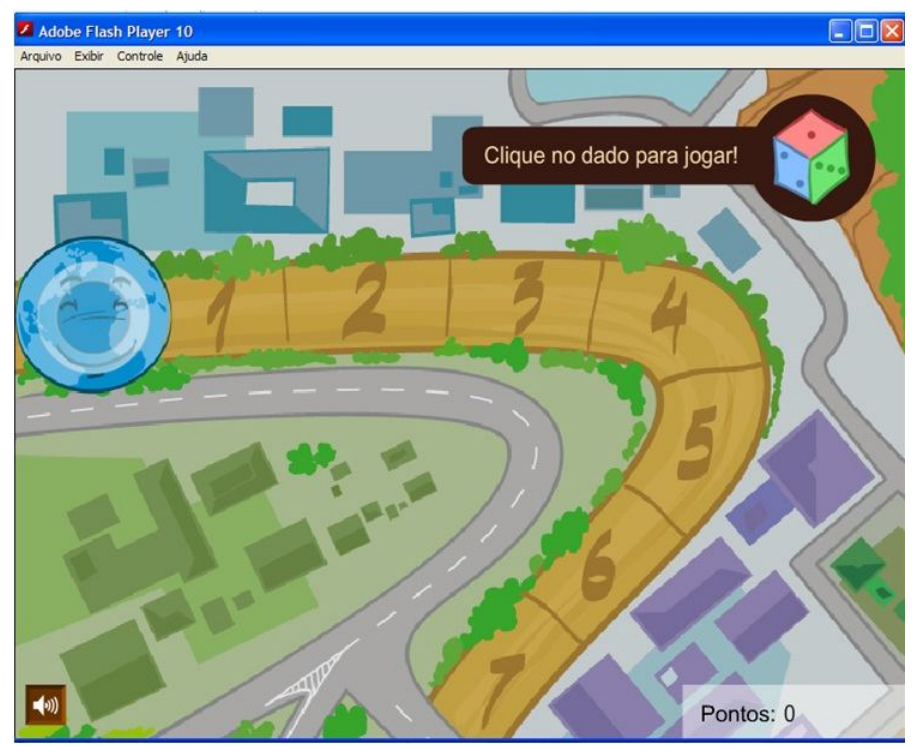

Figura 2: Tela inicial do Jogo Virtual Consumo Consciente.

Ao final do percurso no tabuleiro, o jogador receberá uma mensagem sobre seu desempenho em relação ao percentual de acerto das perguntas do jogo, bem como será informado sobre as opções de "jogar novamente" ou acessar um link que o direcionará a um hotsite de complemento do jogo. Nesse hotsite será possível encontrar todas as dicas e perguntas existentes no jogo virtual, definição de consumo consciente, dicas sustentáveis e informações sobre coleta seletiva, além de um formulário para que 
o internauta possa interagir fornecendo suas próprias dicas de consumo consciente, as quais, após análise do administrador do site, serão disponibilizadas para consulta (Figura 4).

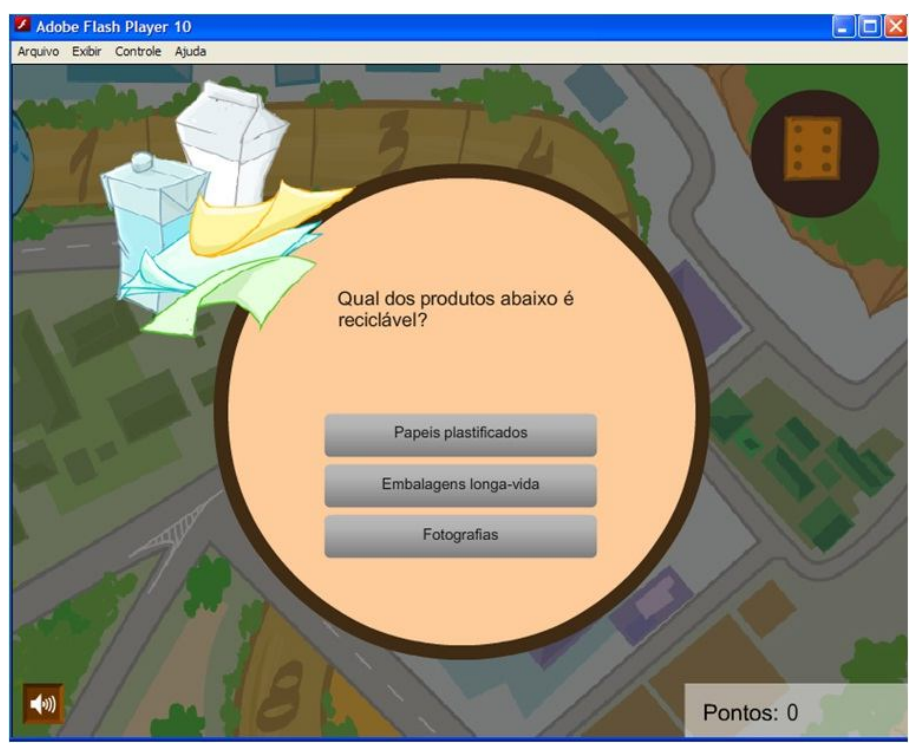

Figura 3: Tela do Jogo Virtual com pergunta.

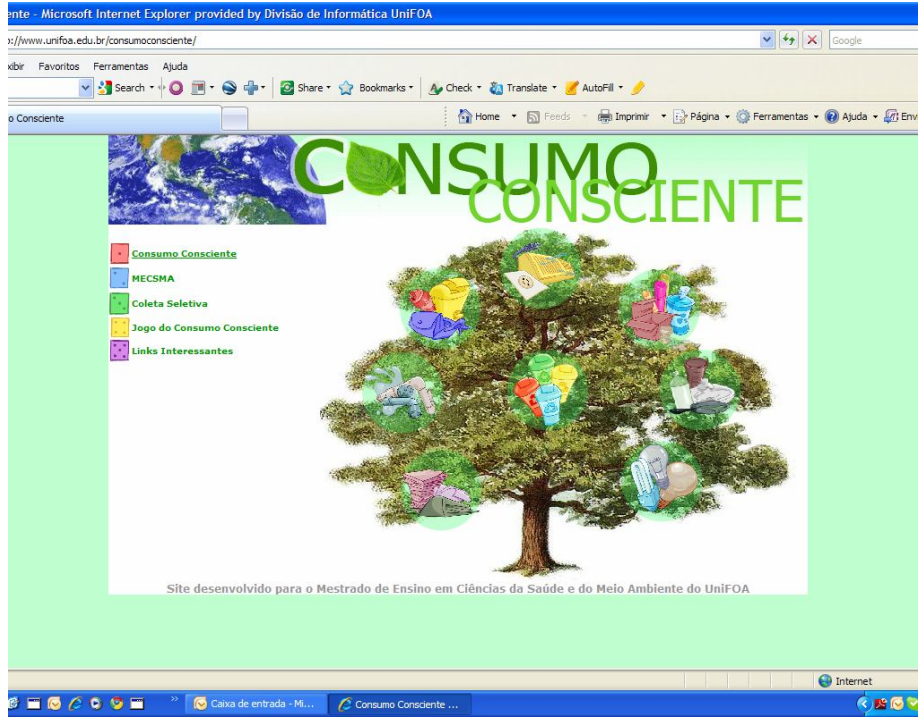

Figura 4: Página inicial do site sobre consumo consciente.

\section{CONSIDERAÇÕES FINAIS}

O consumo consciente é um tema bastante discutido nas empresas, nas instituiç̧ões de ensino e nos lares de vários brasileiros.

O marketing, através de estratégias de promoção de vendas e merchandising, publicidade e propaganda entre outras ferramentas, muitas vezes é responsabilizado de 
ser o vilão que incita as pessoas a comprarem excessivamente bens materiais. Mas não é só isso. O crédito fácil e o conforto gerado pelos diversos aparelhos elétricos e eletrônicos têm demonstrado que consumir conscientemente é uma tarefa difícil, principalmente quando nosso grupo de referência nos leva a acreditar que é preciso possuir bens para ser aceito e reconhecido na sociedade.

No entanto, acreditamos que a conscientização contínua é capaz de proporcionar mudanças de comportamento significativas.

Considerando os resultados obtidos até o momento, é possível concluir, a partir da pesquisa de campo realizada entre os funcionários do Centro Universitário de Volta Redonda - UniFOA, que os mesmos possuem conhecimentos prévios de consumo consciente bastante consistentes. E também associaram a campanha educativa realizada pela instituição a uma ação importante capaz de garantir saúde financeira para as instituições de ensino e a preservação do meio ambiente.

Como este jogo foi resultado de um produto final de um Mestrado Profissional em Ensino em Ciências da Saúde e do Meio Ambiente, e se encontra hospedado na página do Centro Universitário do referido curso, sugere-se também que o mesmo seja trabalhado na instituição dentro das diferentes graduações. O produto pode também ser levado pelos profissionais de ensino para o ensino básico.

\section{REFERÊNCIAS}

CAHAPUZ, A.; GIL-PEREZ, D.; CARVALHO, A. M. P.; PRAIA, J. E VILCHES, A. (orgs.) (2005) - A necessária renovação do ensino de Ciências. São Paulo: Cortez. DIAS, Genebaldo Freire. Educação Ambiental: princípios e práticas. $9^{a}$ ed. São Paulo: Gaia, 2004. 551 p.

GRAMIGNA, Maria Rita. Jogos de Empresa. $2^{\text {a }}$. ed. São Paulo: Pearson Prentice Hall, 2007. $180 \mathrm{p}$.

HUIZINGA, J. Homo ludens: o jogo como elemento da cultura. São Paulo: Perspectiva, 1971.

JACOBI, Pedro. Educação Ambiental, Cidadania e Sustentabilidade. Cadernos de Pesquisa, São Paulo, n. 118, p. 189-205, mar. 2003. JUNIOR, Arlindo Philippi. PELICIONI, M. Cecília Focesi. Educação Ambiental: Desenvolvimento de Cursos e Projetos. $2^{a}$. ed. São Paulo: Universidade de São Paulo. Faculdade de Saúde Pública. Núcleo de Informações em Saúde Ambiental. Signus Editora, 2002. 349 p.

KANAAENE, Roberto, ABUSSANRA, Janaina. Jogos em treinamento e desenvolvimento do potencial humano. Integração, ano XIV, n. 52, p. 83-93, jan/fev/mar. 2008.

KAWASAKI, C.S. et al. A Pesquisa em Educação Ambiental nos ENPECs: contextos educacionais e focos temáticos. Anais do VII ENPEC - Encontro Nacional de Pesquisadores em Educação em Ciências, UFSC, Santa Catarina, 2009. 
KAWASAKI, C.S. ; Carvalho, L. M. Tendências da pesquisa em Educação Ambiental. Educ. rev., v.25, n.3, 2009.

KISHIMOTO, T.M. Jogo, Brinquedo, brincadeira e a educação. São Paulo: Cortez, 2001.

MORTIMER, E. F. (1994) - Construtivismo, mudança conceitual e ensino de ciências: para onde vamos? - Trabalho apresentado na III Escola de Verão de Prática de Ensino de Física, Química e Biologia - Serra Negra, SP.

RODRIGUES, Gelze Serrat de Souza Campos. COLESANTI, Marlene T. de Muno.

Educação ambiental e as novas tecnologias de informação e comunicação. Sociedade e Natureza, Uberlândia, v. 20, n. 1, p. 51-66, jun. 2008.

SILVEIRA, Sidney Renato; BARONE, Dante Augusto Couto. Jogos Educativos Computadorizados Utilizando a Abordagem de Algoritmos Genéticos. Disponível em: http://www.c5.cl/ieinvestiga/actas/ribie98/151.html Acesso em: 20 Jun 2011 